\title{
OXIDATIVE STRESS IN PARKINSON'S DISEASE
}

\author{
Shashikant Nikam, Padmaja Nikam, S K Ahaley and Ajit V Sontakke* \\ Department of Biochemistry, Government Medical College, Miraj and * KIMS, Karad Maharashtra, India
}

\begin{abstract}
Oxidative stress contributes to the cascade, leading to dopamine cell degeneration in Parkinson's disease. However, oxidative stress is intimately linked to other components of the degenerative process, such as mitochondrial dysfunction, excitotoxicity, nitric oxide toxicity and inflammation. It is therefore difficult to determine whether oxidative stress leads to or is a consequence of, these events. Oxidative stress was assessed by estimating lipid peroxidation product in the form of thiobarbituric acid reactive substances, nitric oxide in the form of nitrite \& nitrate. Enzymatic antioxidants in the form of superoxide dismutase, glutathione peroxidase, catalase, ceruloplasmin and non enzymatic antioxidant vitamins e.g. vitamin $E$ and $C$ in either serum or plasma or erythrocyte in 40 patients of Parkinson's disease in the age group 40-80 years. Trace elements e.g. copper, zinc and selenium were also estimated. Plasma thiobarbituric acid reactive substances and nitric oxide levels were Significantly high but superoxide dismutase, glutathione peroxidase, catalase, ceruloplasmin, vitamin-E, vitamin-C, copper, zinc and selenium levels were significantly low in Parkinson's disease when compared with control subjects. Present study showed that elevated oxidative stress may be playing a role in dopaminergic neuronal loss in substentia nigra pars compacta and involved in pathogenesis of the Parkinson's disease.
\end{abstract}

\section{KEY WORDS}

Oxidative stress, Antioxidants, Pathogenesis, Parkinson's disease.

\section{INTRODUCTION}

The emmerging challenge in understanding the pathogenesis of Parkinson's disease includes abnormalities in cellular protein transport, interaction between proteins and protein aggregation (1). Recent advances in both molecular genetics and neurochemistry have shown involvement of excitotoxicity and oxidative stress in cell death (1).

Parkinson's disease is pathologically characterized by loss of catecholaminergic neurons in the brainstem. Number of biochemical processes are involved in pathogenesis and progression of neurological disorders. The concept of oxidative stress and antioxidants may be directly or indirectly involved in the pathogenesis of Parkinson's disease $(2,3,4)$.

\section{Address for Correspondence:}

\section{Dr. Shashikant Nikam}

Department of Biochemistry

Belgaum Institute of Medical Sciences

Civil Hospital Campus, Belgaum-590001 (Karnataka)

E-mail; drshashi9@ hotmail.com
Clinical features of Parkinson's disease are tremors of hands, neurographia, bradikinesia, hypokinesia and akinesia. The pathological hallmarks of Parkinson's disease are presence of Lewy bodies, degeneration of brain stem nuclei and loss of dopaminergic neurons $(5,6)$. Parkinson's disease can be caused due to exogenous neurotoxins, infectious agents, mitochondrial hypothesis, genetic hypothesis, and endogenous neurotoxins (7).

Recent studies showed that oxidative stress damages neurons by free radicals and play an important role in substentia nigra $(8,9)$. Antioxidant substances have role to protect cell from pathogenic oxidation. These are superoxide dismutase, glutathione peroxidase, catalase, ceruloplasmin, vitamin $\mathrm{E}$ and C. Trace elements are required in a small concentration for activation of antioxidant enzymes. Considering all these facts we planned to study certain relevant biochemical parameters for understanding the pathogenesis of Parkinson's disease.

\section{MATERIALS AND METHODS}

The present study was carried out with 40 clinically examined 
Parkinson's disease patients ranging in age group 40-80 years, admitted in Govt. Medical College Hospital Miraj. Patients heaving obvious malignancy, hepatic, renal, or cardiac disease were excluded from the study. Written consent was obtained from patients as well as controls. Diagnosis of Parkinson's disease was done by physicians and confirmed by senior neurologist of government medical college and hospital Miraj. Age and sex matched 40 normal healthy persons as per IFCC guidelines were included as control subjects. All chemicals used in this study were of analytical grade.

Malondialdehyde standard was procured taken from sigma chemicals USA, superoxide dismutase (SOD) and glutathione peroxidase (GSHPx) standards were taken from Randox Lab.U.K. Catalase standard was obtained from BDH biochemicals U.K. vitamin $E$ and L-ascorbic acid from SRL chemicals Ltd. India. All other chemicals purchased locally were analytical grade only.

Fasting blood samples were collected under sterile condition from healthy controls and Parkinson's disease patients, just before starting any drug treatment. $8 \mathrm{ml}$ blood was taken in EDTA vials and $5 \mathrm{ml}$ in plain bulbs, plasma was separated for the estimation of thiobarbituric acid reactive substances (TBARS), vitamin- E, vitamin-C and ceruloplasmin. Erythrocytes were washed with cold isotonic saline and used for estimation of SOD, GSHPx, and catalase. Sera were separated and used for nitric oxide (nitrate + nitrite), copper, zinc and selenium.

TBARS were estimated in plasma as described by Buege (10) employing MDA as a reference standard. TBARS levels were expressed as $\mathrm{n}$ mole / $\mathrm{ml}$ plasma. Serum nitric oxide was estimated as the stable breakdown product, nitrate and nitrite by Cortas and Walkid (11) employing potassium nitrate as a reference standard. Levels of nitric oxide were expressed as $\mu$ mole/Lit. SOD was assayed in RBC according to RANSOD kit U.K. SOD activity was expressed as Units/gm of $\mathrm{Hb}$ (12). GSHPx was assayed in RBC by UV method of Ransel kit U.K. GSHPx activity was expressed as Units/gm of $\mathrm{Hb}$ (13), Catalase was estimated in erythrocytes hemolysate, according to method of Aebi (13). Its activity was expressed as n mole / $\mathrm{H}_{2} \mathrm{O}_{2}$ decomposed/min. Levels of Ceruloplasmin were estimated by colorimetric method by Karl (14). Levels of ceruloplasmin were expressed as units/L plasma.

Concentration of vitamin $\mathrm{E}$ was estimated in plasma according to the method of Beaker and Frank (15) and values were expressed as $\mathrm{mg} / \mathrm{dl}$ of plasma. Concentration of vitamin C was estimated in plasma by method of Natelson (16), and values of vitamin- $C$ were expressed as $\mathrm{mg} / \mathrm{dl}$ plasma. Serum Copper, Zinc and Selenium levels were estimated by Atomic Absorption Spectrophotometer (AAS), Parkin Elmer model 3030 , and values of these trace elements were expressed as $\mu \mathrm{gm} / \mathrm{dl}$.

All results were expressed in mean \pm SD. Student's Newman Keul test was applied to judge the significance of difference between two groups.

Table 1: Oxidative Stress and Antioxidant levels in Control and Subjects with Parkinson's Disease

\begin{tabular}{|c|c|c|c|}
\hline Sr.No. & Parameters & $\begin{array}{l}\text { Healthy Control } \\
\qquad(n=40) \\
\text { Mean } \pm S D\end{array}$ & $\begin{array}{c}\text { Parkinson's } \\
\text { disease }(n=40) \\
\text { Mean } \pm S D\end{array}$ \\
\hline 1 & LPO (n moles/ml) & $2.20 \pm 0.640$ & $5.20^{\star \star} \pm 0.875$ \\
\hline 2 & $\begin{array}{l}\text { Nitric Oxide (NO) } \\
(\mu \text { mole/Lit) }\end{array}$ & $285.35 \pm 1.09$ & $332.03^{*} \pm 103.83$ \\
\hline 3 & SOD (U/gm of $\mathrm{Hb})$ & $3.05 \pm 0.82$ & $2.32^{\star *} \pm 0.605$ \\
\hline 4 & GSHpx (U/gm of $\mathrm{Hb})$ & $58.25 \pm 5.58$ & $40.85^{\star *} \pm 3.98$ \\
\hline 5 & $\begin{array}{l}\text { Catalase }\left(\mathrm{nmole} / \mathrm{H}_{2} \mathrm{O}_{2}\right. \\
\text { decomposed } / \mathrm{min})\end{array}$ & $640 \pm 110.05$ & $507.87^{* *} \pm 115.0$ \\
\hline 6 & Ceruloplasmin $(\mathrm{U} / \mathrm{L})$ & $105.50 \pm 18.15$ & $97.58^{\star} \pm 12.18$ \\
\hline 7 & Vitamin-E (mg/dl) & $7.86 \pm 2.52$ & $5.58^{\star} \pm 2.77$ \\
\hline 8 & Vitamin-C (mg/dl) & $1.66 \pm 0.46$ & $0.77^{\star} \pm 0.14$ \\
\hline 9 & Copper ( $\mu \mathrm{g} / \mathrm{dl})$ & $105.0 \pm 14.45$ & $92^{*} \pm 9.3$ \\
\hline 10 & $\operatorname{Zinc}(\mu \mathrm{g} / \mathrm{dl})$ & $98.50 \pm 8.25$ & $75.70^{*} \pm 9.20$ \\
\hline 11 & Selenium $(\mu \mathrm{g} / \mathrm{dl})$ & $19.05 \pm 1.42$ & $16.78^{*} \pm 0.98$ \\
\hline
\end{tabular}

Values are mean \pm SEM of number of observations $(n)$. ** indicates $p<$ 0.001 when compared with normal healthy control * indicates $p<0.01$ when compared with normal healthy control.

Table 1 shows the mean $\pm S D$ of the various parameters studied in patients and controls. Mean plasma levels of TBARS (Table 1) were high in Parkinson's disease (PD) patients when compared with control subjects. Serum nitric oxide (nitrate + nitrite) levels were high in PD when compared with control subjects. And the values of TBARS and nitric oxide were statistically significant when compared with control subjects. Erythrocytes SOD and GSHPx activities were significantly lowered in PD as compared with control subjects. Activity of erythrocyte catalase was lowered in PD as compared with control subjects. Ceruloplasmin levels in plasma were significantly lowered in Parkinson's disease when compared with control subjects. The levels of vitamin $E$ and vitamin $C$ in plasma were significantly lowered in PD when compared with control subjects. The levels of trace elements copper, zinc and selenium in serum were significantly lowered in Parkinson's disease when compared with control subjects. 


\section{DISCUSSION}

Free radicals have been accepted into the biochemical and medical orthodoxy. Their existence and importance in living systems was ignored (17). Oxidative stress has been implicated in the pathophysiology of many neurological disorders $(18,19)$.

Our study shows certain significant findings. Thiobarbutaric acid reactive substances (TBARS), the indicator of lipid peroxidation (LPO) was significantly elevated in Parkinson's diseases (Table 1). The metabolism of dopamine by action of enzyme monoamine oxidase is accelerated in Parkinson's disease and excessive formation of hydrogen peroxide $\left(\mathrm{H}_{2} \mathrm{O}_{2}\right)$ takes place. In subsequent reactions $\mathrm{H}_{2} \mathrm{O}_{2}$ hydroxyl radicals are generated. As per reports, the activity of monoamine oxidase is increased in Parkinson's disease (20). This increased activity of monoamine oxidase may further metabolizes dopamine to produce excessive formation of hydrogen peroxide. The polymerization of auto-oxidative products of dopamine may lead to the formation of characteristic pigmentation of the substantia nigra. These released free radicals might be responsible for the loss of dopaminergic neurons.

Activity of nitric oxide synthase (NOS) is enhanced by Nmethyl - D - aspartate, which in turn leads to enhanced generation of nitric oxide. It combines with superoxide radical to form peroxynitrate $(21,22)$. This peroxynitrate increases oxidative stress, which might be causing loss of dopaminergic neurons.

Enzymatic antioxidant status was studied by estimating erythrocyte SOD, GSHPx, catalase activity and serum ceruloplasmin levels. SOD activity and serum zinc levels were decreased in Parkinson's disease (Table 1). Zinc stabilizes the structure of SOD and hence when zinc ions are removed, it results in loss of SOD activity (23). Thus low zinc levels might be responsible for reduced SOD activity and increase concentration of superoxide radicals. This suggests that an increased formation of superoxide radicals in proximity to mitochondria induce an increase in superoxide dismutase activity. These superoxide radicals combine with nitric oxide and elevate oxidative stress.

Activity of GSHPx and selenium levels were decreased in Parkinson's disease (PD). GSHPx contains selenium in the form of single selenocysteine residue (23). This decreased selenium concentration may decrease the activity of GSHpx, in PD than in control subjects. The increased oxidative stress may oxidize hemoprotein subunit of catalase. Due to oxidation, there may be dissociation of tetrameric hemoprotein molecule which and results in loss of catalase activity. Thus, elevated oxidative stress may decrease the activity of catalase. Elevated oxidative stress may inhibit synthesis of ceruloplasmin, which might be responsible for reduced levels of Ceruloplasmin in PD.

Levels of vitamin $E$ and $C$ were decreased in PD than in healthy control subject. Due to increased oxidative stress in PD there may be increased consumption of vitamin $E$ and $C$. Vitamin $E$ traps free radicals and interrupts the chain reaction that damage the cells (24). This decreased vitamin $E$ and $C$ might be causing oxiradical mediated injury and thus may contribute to nigral neurodegeneration.

In conclusion, the present data indicate that, oxidative stress and antioxidants might be playing an important role in PD. Elevated oxidative stress may cause neuronal loss and play a role in pathogenesis of Parkinson's disease. The decreased activity of these enzymes indirectly responsible for neuronal loss and probably plays a role in pathogenesis of Parkinson's disease.

\section{REFERENCES}

1. Martin JB. Moleculor basis of the neurodegenerative disorder. New Eng J Med 1999 ;340 (25):1970-80.

2. Pioro EP. Antioxidant therapy in ALS. Amyotrophic Lateral Scleorsis 2000; 1 (Supl): 5-15.

3. Kowall W, Ferante RJ, Martin JB. Patterns of cells in Huntington's disease. Trends Neurosci 1987 ;10: 42-9.

4. Mmosley RL, Benner EJ, Irena. Neuroinflammation,oxidative stress and the pathogenesis of Parkinson's disease. Clin Neurochem Res 2006; 6 (5):261- 181.

5. Jellinger K. Pathology of Parkinson's disease, changes other than the nigrostritalpathway. Ann Neural 1992; 14: 153-97.

6. Forne LS. Pathology of Parkinson's disease and importance of substentia nigra and Lewy bodies. Aetiology of Parkinson's disease. Ed.Sterm. G.Baltimore Johns Hopkins Press: 1990; p 185-238.

7. Kurtz JF. An overview of epidemiology of Parkinsonism. Progress inParkinson's disease research. Eds. Hefti F.Weiner W.J.Mount Kisw Futura Publishing Company. 1992; p-119-69.

8. Munch G. Oxidative stress and advanced glycation end products. Alzheimer's Disease Review 1996;1:71-4.

9. Benecke R, Strumper P, Weiss H. Electron transport complex $\mathrm{Cl} \&$ IV of platelets are abnormal in Parkinson's disease. Brain 1993;116;1451-63. 
10. Buege JA, Aust AD. Microsomal lipid peroxidation.In methods Enzymeol Estbrook RW, Pullman ME. New York: Acad Press $1987 ; 302-10$

11. Cortas, Walkid. Determination of nitrate in serum and urine by kinetic cadmium reduction method. Clin Chem 1990;38 (8pt.1); 1440-43.

12. Randox Ltd. Determination of superoxide dismutase \& Glutathione peroxide. Tech Bull on free radical 1994; $12-14$.

13. Aebi H. Catalase. In methods, in enzymatic analysis (ed) Bergmeryer HU. Vol. 3. Acadamic press New York 1983; 276-86.

14. Karl H, Smith BSW, Wright $H$. Colorimetric method for serum Ceruloplasmin. Clin Chem 1974 ;50: 359-66.

15. Baker Frank. Vitamin E. In clinical vitaminology methods \& interpretation, Interscience publishers, New York 1968; 169-76.

16. Natelson S. Ascorbic acid. In techniques of clinical chemistry, 3rd Edition,Charles C Thomas, Illinios USA 1971;162-5.

17. Fahn S. Parkinson's disease and other basal ganglion disorders. IN: Disease of nervous system. Clin Neurol. Eds.: Asbury AK et.al.W.B.Saunders company. 1992; 1144-58.
18. Ratan RR, Baraban JM. Apoptotic death in an invitro model of neuronal oxidative stress. Clin Ext Pharmacol Physical 1995; 309-10.

19. Mecocci. The oxidative damage mitochondrial DNA shows age dependent increase in human brain. Ann Neural 1993:34; 159-63.

20. Floryed RA Antioxidants,oxidative stress and degenerative neurological disorders. Proc Soc Exper Biol Med 1999; 222(3): 236-45

21. Behl C, Davis J, Cole GM. Vitamin E protects nerves cells from amyloid beta protein toxicity. Biochem Biophy Res Commun 1992; 186: 944-50.

22. Brown R. ALS and the inherited motor neurons disease. Mol Neurol. New York Scientific Americam 1998; 223:38.

23. Burke RE. Apoptosis in degenerative disease of the basal ganglia. Neurosciertist 1998; 4:301-11.

24. Bhumik D, Medin J, Colmenms G. Mutational analysis of active site residue of human adenosine deaminase. J Biol Chem 1993; 8268: 5461-70. 